\title{
Arthroplasty Utilization in the United States is Predicted by Age-Specific Population Groups
}

\author{
Bronislava Bashinskaya, ${ }^{1,2}$ Ryan M. Zimmerman, ${ }^{1}$ Brian P. Walcott, ${ }^{3}$ and Valentin Antoci ${ }^{1}$ \\ ${ }^{1}$ Department of Orthopedic Surgery, Massachusetts General Hospital, Harvard Medical School, Boston, MA 02114, USA \\ ${ }^{2}$ Boston University, Boston, MA 02215, USA \\ ${ }^{3}$ Department of Neurosurgery, Massachusetts General Hospital, Harvard Medical School, 55 Fruit Street, \\ White Building Room 502, Boston, MA 02114, USA \\ Correspondence should be addressed to Brian P. Walcott, walcott.brian@mgh.harvard.edu
}

Received 1 October 2012; Accepted 17 October 2012

Academic Editors: J. Gallo, M. Hasegawa, and J. D. Lurie

Copyright () 2012 Bronislava Bashinskaya et al. This is an open access article distributed under the Creative Commons Attribution License, which permits unrestricted use, distribution, and reproduction in any medium, provided the original work is properly cited.

\begin{abstract}
Osteoarthritis is a common indication for hip and knee arthroplasty. An accurate assessment of current trends in healthcare utilization as they relate to arthroplasty may predict the needs of a growing elderly population in the United States. First, incidence data was queried from the United States Nationwide Inpatient Sample from 1993 to 2009. Patients undergoing total knee and hip arthroplasty were identified. Then, the United States Census Bureau was queried for population data from the same study period as well as to provide future projections. Arthroplasty followed linear regression models with the population group $>64$ years in both hip and knee groups. Projections for procedure incidence in the year 2050 based on these models were calculated to be $1,859,553$ cases (hip) and 4,174,554 cases (knee). The need for hip and knee arthroplasty is expected to grow significantly in the upcoming years, given population growth predictions.
\end{abstract}

\section{Introduction}

As the post-World War II "baby boom" generation ages, a growing percentage of Americans will be living into their eighth decade and beyond [1]. Such demographic shift has significant implications for the design of a new healthcare delivery model $[2,3]$. Medical conditions prevalent in the elderly are of particular interest and will have the greatest impact on the system. These include degenerative conditions, with severe arthritis afflicting over $15 \%$ of the population and estimated to surpass $20 \%$ (or 60 million people) by 2020 $[4,5]$. As osteoarthritides of the knee and hip are known to increase with age, it is not surprising that the majority of knee and hip arthroplasty is performed in the elderly [6-12].

Being in a current state of healthcare reform with specific funding allocations being made, the understanding of future trends becomes critical. Considering that musculoskeletal complaints are the leading cause of medical claims, (with osteoarthritis encompassing the majority of disability in elderly adults), it is necessary to identify recent trends in arthroplasty and project future utilization needs. We hypothesize that the elderly subpopulation is correlated with arthroplasty utilization and can be used to predict arthroplasty utilization in the future.

\section{Methods/Materials}

The data was analyzed anonymously, using publicly available secondary data; therefore no ethics statement is required for this work. To protect the confidentiality of patients, the dataset suppressed reporting when values were based on 10 or fewer discharges or when fewer than two hospitals in the state were reporting. Incidence data from the US Nationwide Inpatient Sample was queried from 1993 to 2009 (the most recent available year). Weighted national estimates were provided from the Agency for Healthcare Research and Quality (AHRQ), Healthcare Cost and Utilization Project's Nationwide Inpatient Sample (NIS), based on data collected by individual states and provided to the AHRQ. The total 
TABLE 1: ICD-9-CM codes grouped according to clinical classifications software.

\begin{tabular}{lcc}
\hline CCS Code & Procedure & ICD-9-CM Codes \\
\hline \multirow{3}{*}{152} & & $0080 ; 0081 ; 0082 ; 0083 ; 0084 ;$ \\
& Knee arthroplasty & $8141 ; 8142 ; 8143 ; 8144 ; 8146 ;$ \\
& & $8147 ; 8154 ; 8155$ \\
\hline \multirow{3}{*}{153} & \multirow{2}{*}{ Hip arthroplasty } & $0070 ; 0071 ; 0072 ; 0073 ; 0074 ;$ \\
& & $0087 ; 8151 ; 8152 ; 8153 ; 8169$ \\
\hline
\end{tabular}

number of weighted discharges in the USA is based on the NIS total of $=39,434,956$. Statistics based on estimates with a relative standard error (standard error/weighted estimate) greater than 0.30 were excluded. Statistics were only based on hospitals that meet the definition of "community hospital" - nonfederal, short-term, general, and other specialty hospitals, including public hospitals and academic medical centers. Federal, rehabilitation, and psychiatric hospitals, as well as alcoholism/chemical dependency treatment facilities were excluded from analysis.

The principal procedure was defined as the definitive treatment during the hospital admission (not diagnostic or exploratory). The unit of analysis was discharge: if a particular procedure occurred multiple times during the same admission, it was only counted once. Knee and hip arthroplasty were identified as principal procedures using clinical classifications software (CCS) of ICD-9-CM codes 152 and 153, respectively, [13] (Table 1). Information regarding incidence, combining both primary and revision procedures, was extracted. The United States Census Bureau was queried for population data from the same study period [14] and also used to provide future projections [15].

Statistical analysis was performed using the R programming environment version 2.15.1 (R Core Team (2012). R: a language and environment for statistical computing. $\mathrm{R}$ Foundation for Statistical Computing, Vienna, Austria. ISBN 3-900051-07-0, URL http://www.R-project.org/). To test our first hypothesis, we identified three population groups based on available United States Census data: total population, population over 64 years of age, and population over 84 years of age. These values were then used to generate individual scatterplots to allow for a visual interpretation between the variables. A linear relationship was assumed based on the distribution of the plotted variables. A Pearson productmoment correlation coefficient was then calculated for each of the three population groups to determine the strength of association.

To analyze the ability of population trends to predict future arthroplasty incidence, linear regression analysis, fitted using the least squares approach, was utilized. Models were created for each of the various population groups to extract individual regression coefficients and R-squared values. An analysis of variance table was used to compare the different models. Visual regression diagnostics were performed by plotting residual versus fitted values, standardized residuals versus theoretical quantiles, square root of standardized residuals versus fitted values, and standardized residuals versus leverage. Finally, using the regression formula, arthroplasty trends in future years were predicted using estimated population data from the United States Census Bureau [15].

\section{Results}

17 years of data (1993-2009) were available in the Nationwide Inpatient Sample, providing incidence data for hip and knee arthroplasty. The incidence of hip arthroplasty ranged from 260,200 to 436,700 cases per year (median 329,900 \pm standard error 13773). The incidence of knee arthroplasty ranged from 279,101 to 680,839 (median 363,536 \pm standard error 34,330 ) (Figure 1). Scatterplots were also generated assuming a linear relationship between procedure incidence and the three population groups (Figures 2 and 3 ). A Pearson product-moment correlation coefficient matrix revealed the strongest association between arthroplasty (both hip and knee) and population subgroup "greater than 64 years of age" (Table 2).

Linear regression models were then created for each of the various age groups and the incidence of operative procedures (Figures 1 and 2). The $X$ value of "population > 64 years" was the most accurate model for both hip arthroplasty and knee arthroplasty based on $R$-squared analysis (Table 3). Arthroplasty followed a linear model with the population group $>64$ years in both hip and knee groups; $R^{2}=0.969$ and 0.944 , respectively. An analysis of variance table revealed that "population > 64 years" consistently resulted in the smallest residual sum of squares in both hip and knee regression models when compared to other $X$ variables (Table 4). Visual regression diagnostics were performed by plotting residual versus fitted values, standardized residuals versus theoretical quantiles, square root of standardized residuals versus fitted values, and standardized residuals versus leverage confirmed that a linear regression analysis was appropriate. Using the regression formula, arthroplasty trends in future years were predicted using estimated population data from the United States Census Bureau (Table 5). Projections for procedure incidence in the year 2050 based on these models were calculated to be $1,859,553$ cases (hip) and 4,174,554 cases (knee).

\section{Discussion}

The population of the United States is growing rapidly, with the proportion of elderly citizens projected to grow even faster as the baby-boomer generation ages. With age, a cumulative "wear and tear" summates at the cellular, organ and population based levels [16-21]. Osteoarthritis is one of the major diseases predicted to expand in this population, along with cancer [22], pneumonia [23], and heart disease $[24,25]$. Joint arthroplasty is one surrogate of advanced osteoarthritis and has been projected to occupy a significant portion of the healthcare expenditure in the next couple decades. Previous investigations have predicted an increase in total joint arthroplasty demand [26]. In a study by Kurtz et al., projections for hip arthroplasty 
TABLe 2: Pearson product-moment correlations.

\begin{tabular}{lcc}
\hline & Hip & Knee \\
\hline Population total & $0.9660183(95 \%$ CI 0.9060745, 0.9879475) & $0.9318893(95 \%$ CI 0.8173353, 0.9755691) \\
Population $>$ 64 years & $0.9844568^{*}(95 \%$ CI 0.9563160, 0.9945204) & $0.9715806^{*}(95 \%$ CI 0.9210546, 0.9899387) \\
Population $>$ 84 years & $0.9723646(95 \%$ CI 0.9231783, 0.9902188) & $0.9489339(95 \%$ CI 0.8609842, 0.9817860) \\
\hline
\end{tabular}

* The strongest correlation and the narrowest $95 \%$ confidence intervals (CI).

TABle 3: (a) Regression Analysis— - hip arthroplasty. Formula: (procedure incidence $=$ coefficient $(X)+$ intercept). (b) Regression analysis— knee arthroplasty. Formula: (procedure incidence $=\operatorname{coefficient}(X)+$ intercept).

(a)

\begin{tabular}{lccc}
\hline$X$ & Coefficient & Intercept & $R$-squared \\
\hline Population total & $3.333 e-03 \pm 2.302 e-04$ & $-6.074 e+05 \pm 6.514 e+04$ & 0.933 \\
Population $>$ 64 years & $2.880 e-02 \pm 1.327 e-03$ & $-6.906 e+05 \pm 4.726 e+04$ & 0.969 \\
Population $>84$ years & $9.722 e-02 \pm 6.027 e-03$ & $-8.784 e+04 \pm 2.636 e+04$ & 0.945 \\
\hline
\end{tabular}

(b)

\begin{tabular}{lccc}
\hline$X$ & Coefficient & Intercept & $R$-squared \\
\hline Population total & $8.013 e-03 \pm 8.053 e-04$ & $-1.842 e+06 \pm 2.278 e+05$ & 0.868 \\
Population $>$ 64 years & $7.085 e-02 \pm 4.457 e-03$ & $-2.099 e+06 \pm 1.588 e+05$ & 0.944 \\
Population $>84$ years & $2.365 e-01 \pm 2.030 e-02$ & $-6.046 e+05 \pm 8.876 e+04$ & 0.901 \\
\hline
\end{tabular}

\pm Standard error.

TABLE 4: (a) Analysis of variance table-hip arthroplasty regression. (b) Analysis of variance table—-knee arthroplasty regression.

(a)

\begin{tabular}{lcc}
\hline$X$ & Degrees of freedom & Residual sum of squares \\
\hline $\begin{array}{l}\text { Population total } \\
\text { Population }>64\end{array}$ & 15 & $3,447,435,118$ \\
$\begin{array}{l}\text { years } \\
\begin{array}{l}\text { Population }>84 \\
\text { years }\end{array}\end{array}$ & 15 & $1,591,638,084$ \\
\hline
\end{tabular}

(b)

\begin{tabular}{lcc}
\hline$X$ & Degrees of freedom & Residual sum of squares \\
\hline $\begin{array}{l}\text { Population total } \\
\text { Population }>64\end{array}$ & 15 & $4.2181 e+10$ \\
$\begin{array}{l}\text { years } \\
\begin{array}{l}\text { Population }>84 \\
\text { years }\end{array}\end{array}$ & 15 & $1.7962 e+10$ \\
\hline
\end{tabular}

were expected to grow over a 25 -year period, with a $174 \%$ and $673 \%$ estimated increase in hip and knee arthroplasty, respectively [26]. We confirm those trends using different methods, primarily taking into account the growing aging population, in order to better predict resource utilization. Complementary studies have assessed historical trends in arthroplasty utilization using different patient populations, which is useful in anticipating future needs [27]. In a study of only Medicare enrollees ( $\geq 65$ years of age) by Cram et al., knee arthroplasty volume increased to a similar extent with the findings of our study [27].

Many additional factors must be considered in conjunction with age when determining the impact of degenerative musculoskeletal conditions on the healthcare systems. Environmental (patient-centered) factors, such as metabolic or inflammatory conditions, contribute significantly to the incidence of osteoarthritis of the weight bearing joints [28, 29]. Therefore, the increasing incidence of hip and knee arthroplasty is more complex than a direct relationship with the proportion of elderly in the population. This holds particularly true in a population where obesity has reached epidemic proportions [30-32]. The combined (and possible synergistic) effect of age, weight, and patient specific factors is likely to account for the overall increase in the incidence of arthroplasty, although this has not yet been rigorously studied.

While genetic predisposition for osteoarthritis exists and we cannot avoid the inherent mechanical stresses of bipedalism [33-38], straightforward interventions have been demonstrated to be effective in tertiary prevention of osteoarthritis and can be extrapolated to primary and secondary prevention as well. Specifically, weight loss reduces symptomatic knee osteoarthritis [39]. Additionally, either aerobic or resistance exercise regimens are effective in improving measures of disability, physical performance, and pain associated with osteoarthritis in older persons [40]. Given the major impact on the national healthcare "bill" and local resource utilization in individual hospitals, improved efforts directed at preventative care are warranted $[36,41]$. 
TABLE 5: Prediction of future arthroplasty utilization.

\begin{tabular}{lccc}
\hline Year & Population $>64$ years (projected) & Hip arthroplasty & Knee arthroplasty \\
\hline 2010 & $40,229,000$ & 467,995 & 751,224 \\
2015 & $46,837,000$ & 658,305 & $1,219,401$ \\
2020 & $54,804,000$ & 887,755 & $1,783,863$ \\
2025 & $63,907,000$ & $1,149,921$ & $2,428,810$ \\
2030 & $72,092,000$ & $1,385,649$ & $3,008,718$ \\
2035 & $77,543,000$ & $1,542,638$ & $3,394,921$ \\
2040 & $81,238,000$ & $1,649,054$ & $3,656,712$ \\
2045 & $84,456,000$ & $1,741,732$ & $3,884,707$ \\
2050 & $88,547,000$ & $1,859,553$ & $4,174,554$ \\
\hline
\end{tabular}

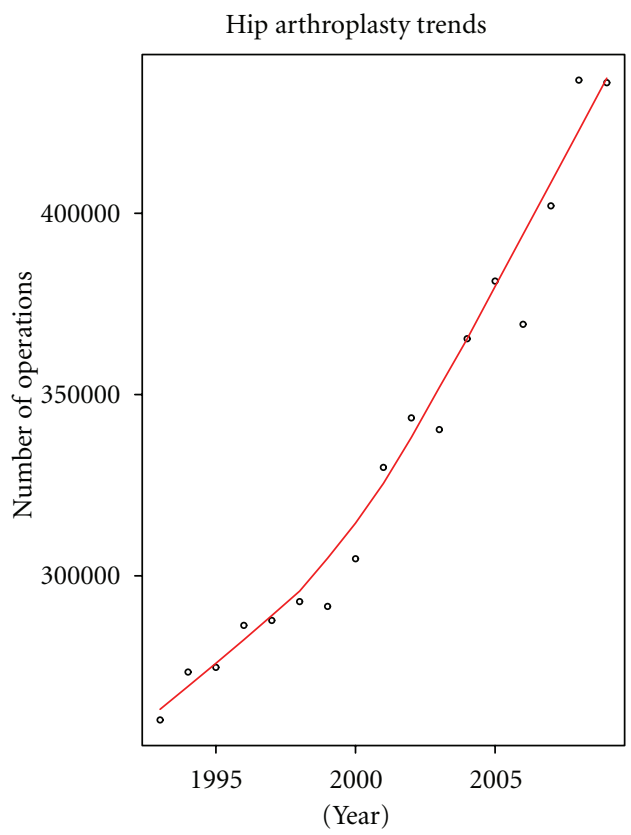

(a)

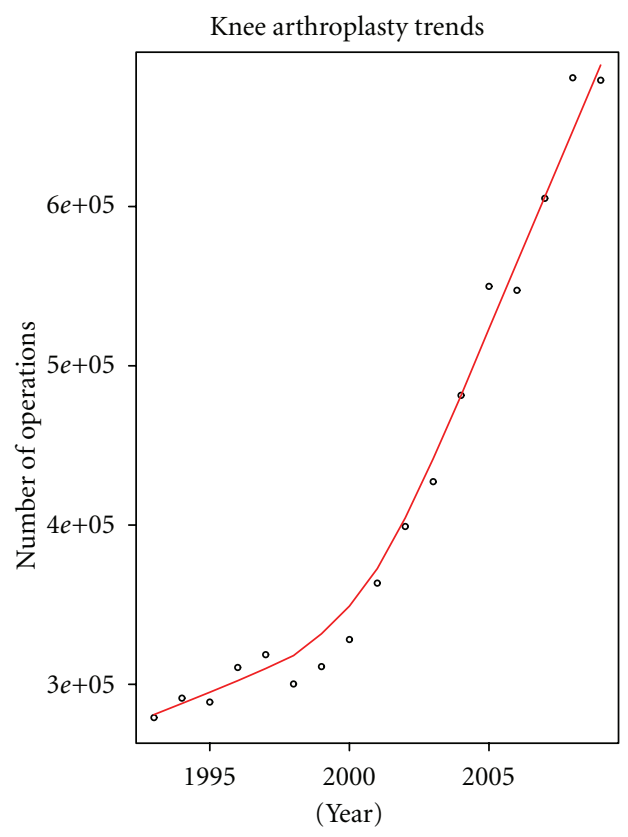

(b)

FIGURE 1: Hip and knee arthroplasty trends over time. Hips and knee arthroplasty incidence has risen in a nonlinear fashion over time. The smoothed scatterplot trend line represents a locally weighted polynomial regression.

Indeed, modification of factors that contribute to symptomatic osteoarthritis, such as obesity, and optimization of other interventions, such as injectables or rehabilitation regimens, may modify the predicted growth in arthroplasty demand.

The main strength of this study includes the use of a well-established national database. Millions of patients are analyzed in a standardized manner over a longitudinal period. Limitations include the national unit of analysis modeling that makes regional differences difficult to account for and that may be influenced by differential reimbursement patterns or socioeconomic factors [42, 43]. It is also impossible to anticipate the effect of medical innovations, scientific discovery, or clinical research that could dramatically alter procedure incidence and result in deviation from the calculated projection model. For example, with the discovery of $H$. pylori as the causative organism for the majority of foregut ulcers, targeted medical therapy has led to a significant decrease in surgical procedures associated with the same [44]. Alternatively, unforeseen clinical efficacy established by reputable clinical trials can lead to changes in surgical procedure incidence [45]. Also to consider are the burgeoning ranks of patients undergoing primary arthroplasty that may portend a dramatic rise in individuals requiring revision arthroplasty, costly procedures not able to be modeled for in this study $[46,47]$. Indications for arthroplasty are dynamic, which limits our accuracy in predicting future surgical volume, although prior studies on this subject have similarly projected arthroplasty growth [26].

This database does not contain information on the degree of severity of osteoarthritis and does not capture other clinical data points such as ancillary treatments, patient weight, mobility status, or time interval from symptom onset to treatment. As with all data recorded in national databases, various coding anomalies are known to exist [48]. 


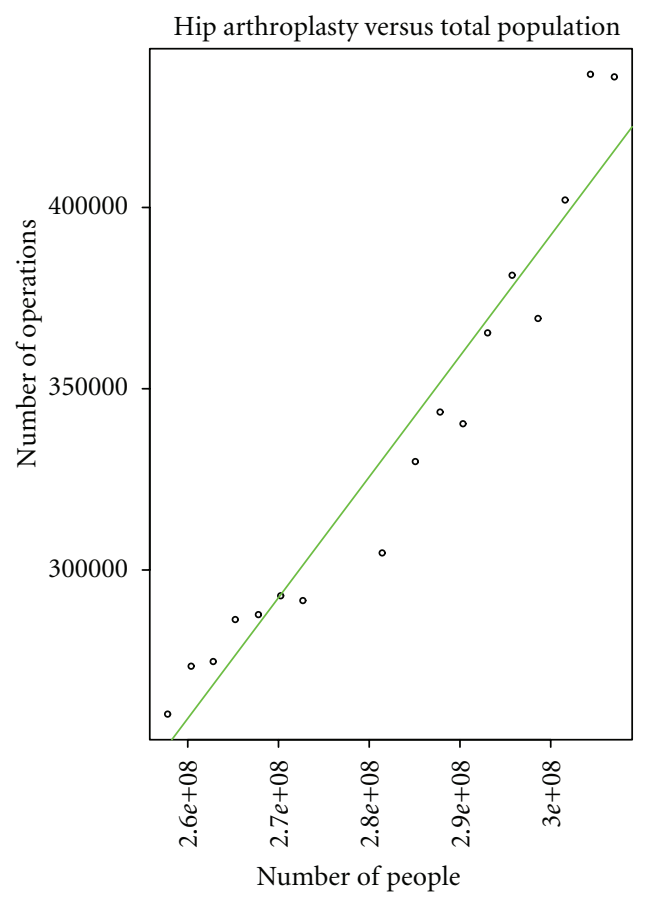

(a)

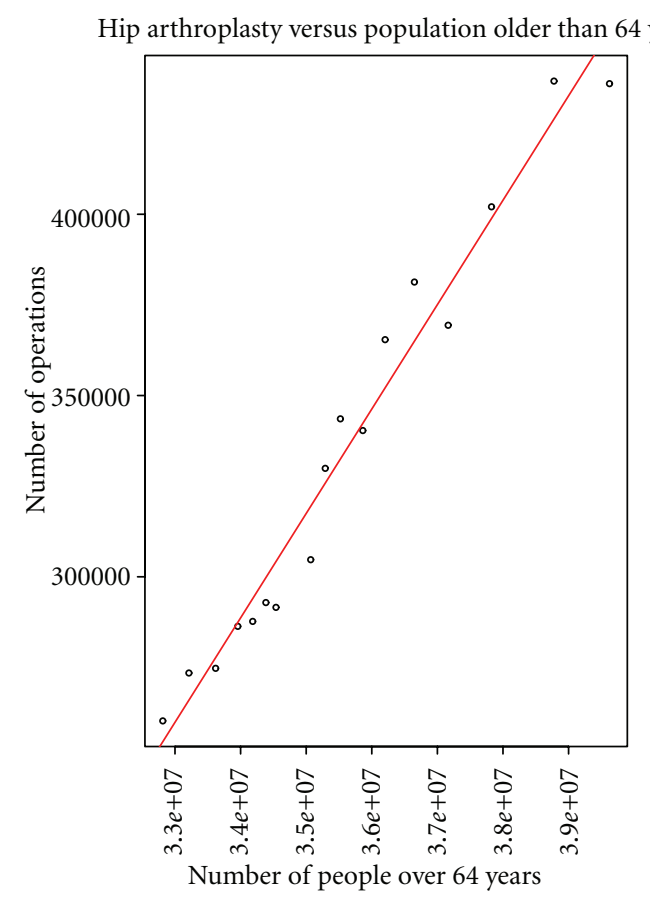

(b)

Hip arthroplasty versus population older than 84 years

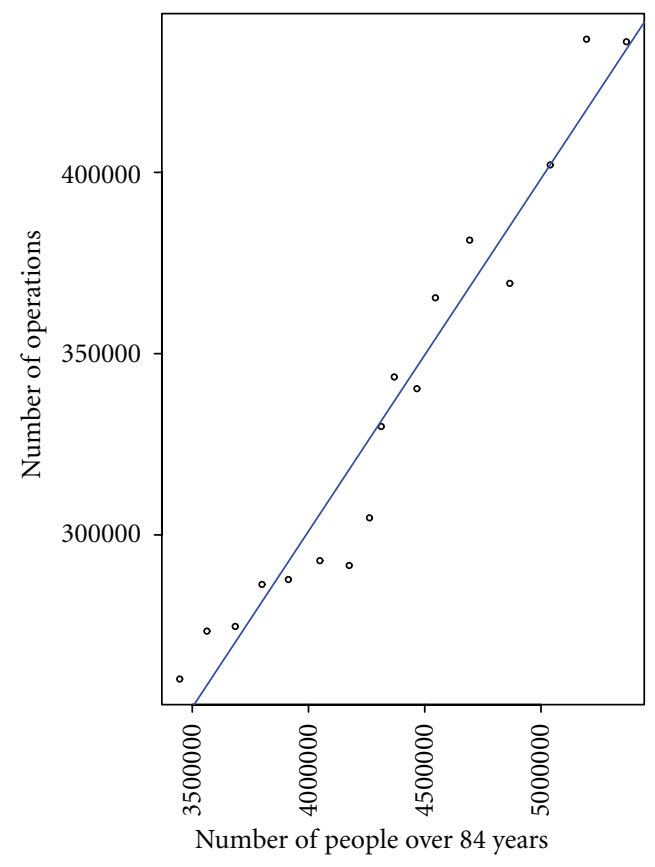

(c)

FIGURE 2: Hip arthroplasty versus population groups. Hip arthroplasty can be predicted by linear regression using the total population ((a)—green regression line), only the population over 64 years of age ((b)—red regression line), and only the population over 84 years of age ((c)—blue regression line). 


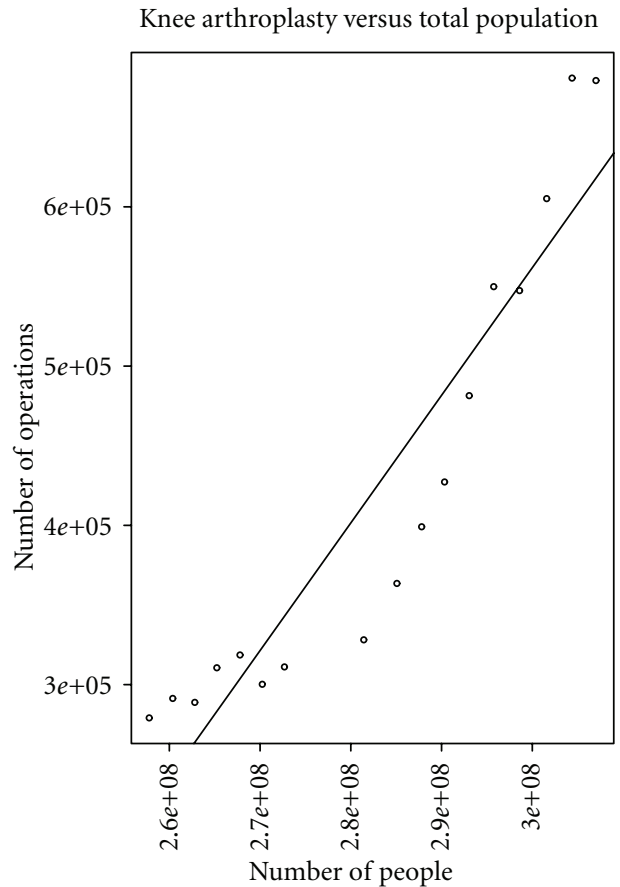

(a)

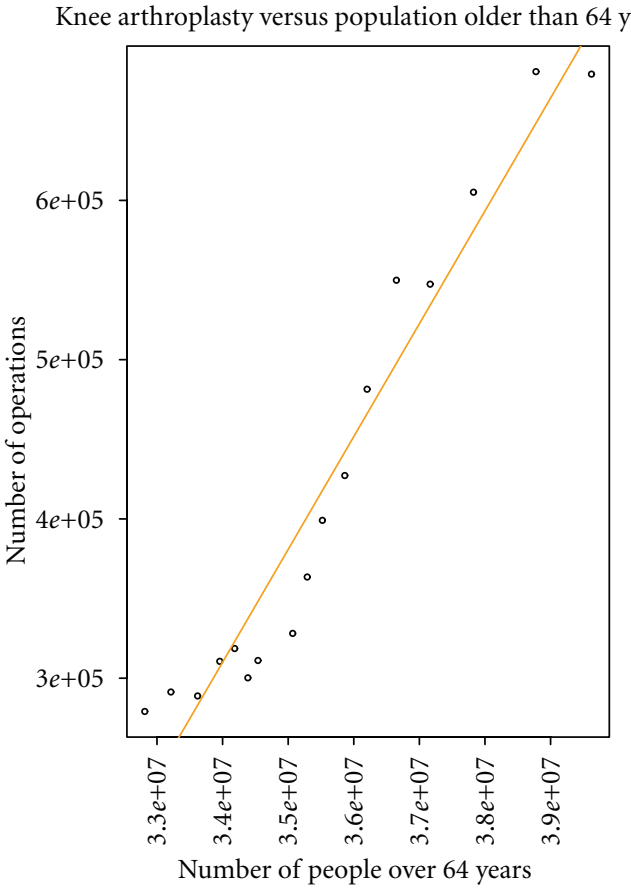

(b)

Knee arthroplasty versus population older than 84 years

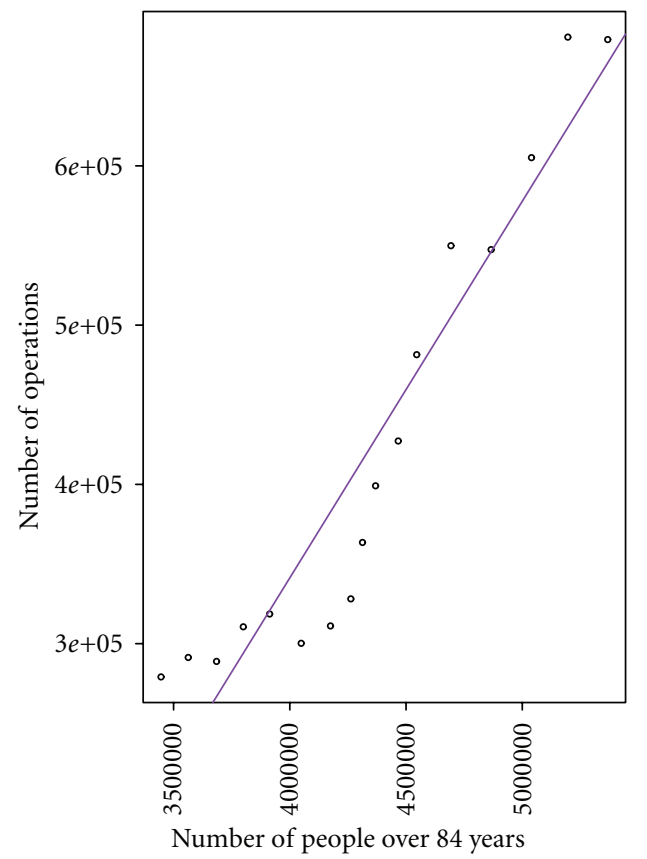

(c)

FIgURE 3: Knee arthroplasty versus population groups. Knee arthroplasty can be predicted by linear regression using the total population ((a) — black regression line), only the population over 64 years of age ((b)—orange regression line), and only the population over 84 years of age ((c)—purple regression line).

We attempted to eliminate this bias by focusing exclusively on the principal diagnosis (i.e., the major determinant of reimbursement rates) with the assistance of CCS grouping that systematically and comprehensively identifies key ICD9-CM procedure codes.

\section{Conclusion}

The demand for knee and hip arthroplasty is expected to rise significantly, given recent trends in practice and predicted increase in the elderly population. Resource allocation and 
surgeon training should prepare physicians to serve these anticipated needs.

\section{References}

[1] R. A. Easterlin, The American Baby Boom In Historical Perspective, UMI, 1968.

[2] S. Keehan, A. Sisko, C. Truffer et al., "Trends: health spending projections through 2017: the baby-boom generation is coming to medicare," Health Affairs, vol. 27, no. 2, pp. w145w155, 2008.

[3] U. E. Reinhardt, "Health care for the aging baby boom: lessons from abroad," Journal of Economic Perspectives, vol. 14, no. 2, pp. 71-83, 2000.

[4] B. Walcott, B. Hanak, J. Caracci et al., "Trends in inpatient setting laminectomy for excision of herniated intervertebral disc: population-based estimates from the US nationwide inpatient sample," Surgical Neurology International, vol. 2, no. 1, article 7, 2011.

[5] J. M. Guralnik, A. Z. LaCroix, R. D. Abbott et al., "Maintaining mobility in late life. I. Demographic characteristics and chronic conditions," American Journal of Epidemiology, vol. 137, no. 8, pp. 845-857, 1993.

[6] D. T. Felson, A. Naimark, and J. Anderson, "The prevalence of knee osteoarthritis in the elderly. The Framingham Osteoarthritis Study," Arthritis and Rheumatism, vol. 30, no. 8, pp. 914-918, 1987.

[7] S. A. Oliveria, D. T. Felson, J. I. Reed, P. A. Cirillo, and A. M. Walker, "Incidence of symptomatic hand, hip, and knee osteoarthritis among patients in a health maintenance organization," Arthritis and Rheumatism, vol. 38, no. 8, pp. 1134-1141, 1995.

[8] N. B. Jain, L. D. Higgins, D. Ozumba et al., "Trends in epidemiology of knee arthroplasty in the United States, 1990 2000," Arthritis and Rheumatism, vol. 52, no. 12, pp. 3928 3933, 2005.

[9] M. Khatod, M. Inacio, E. W. Paxton et al., "Knee replacement: epidemiology, outcomes, and trends in Southern California: 17,080 Replacements from 1995 through 2004," Acta Orthopaedica, vol. 79, no. 6, pp. 812-819, 2008.

[10] K. J. Bozic, S. M. Kurtz, E. Lau et al., "The epidemiology of revision total knee arthroplasty in the united states," Clinical Orthopaedics and Related Research, vol. 468, no. 1, pp. 45-51, 2010.

[11] K. J. Bozic, S. M. Kurtz, E. Lau, K. Ong, D. T. P. Vail, and D. J. Berry, "The epidemiology of revision total hip arthroplasty in the united states," Journal of Bone and Joint Surgery A, vol. 91, no. 1, pp. 128-133, 2009.

[12] K. J. Bozic, P. Katz, M. Cisternas, L. Ono, M. D. Ries, and J. Showstack, "Hospital resource utilization for primary and revision total hip arthroplasty," Journal of Bone and Joint Surgery A, vol. 87, no. 3, pp. 570-576, 2005.

[13] A. Elixhauser, "Most frequent diagnoses and procedures for DRGs, by insurance status. Rockville, Md," Healthcare Cost and Utilization Project (U.S.), U.S. Dept. Health and Human Services, Public Health Service, AHCPR Publications Clearinghouse, Silver Spring, Md, USA, 1996.

[14] USDo Commerce, Population Estimates. Current Estimates Data, 2012.

[15] USDo Commerce, U.S. Population Projections Main, 2012.

[16] V. Lundblad and J. W. Szostak, "A mutant with a defect in telomere elongation leads to senescence in yeast," Cell, vol. 57, no. 4, pp. 633-643, 1989.
[17] J. Campisi, S. H. Kim, C. S. Lim, and M. Rubio, "Cellular senescence, cancer and aging: the telomere connection," Experimental Gerontology, vol. 36, no. 10, pp. 1619-1637, 2001.

[18] J. Campisi, "Cancer and ageing: rival demons?" Nature Reviews Cancer, vol. 3, no. 5, pp. 339-349, 2003.

[19] M. E. T. Dollé, W. K. Snyder, J. A. Gossen, P. H. M. Lohman, and J. Vijg, "Distinct spectra of somatic mutations accumulated with age in mouse heart and small intestine," Proceedings of the National Academy of Sciences of the United States of America, vol. 97, no. 15, pp. 8403-8408, 2000.

[20] R. Ross and J. A. Glomset, "The pathogenesis of atherosclerosis," New England Journal of Medicine, vol. 295, no. 7, pp. 369-377, 1976.

[21] R. A. Miller, "The aging immune system: primer and prospectus," Science, vol. 273, no. 5271, pp. 70-74, 1996.

[22] A. B. Mariotto, K. Robin Yabroff, Y. Shao, E. J. Feuer, and M. L. Brown, "Projections of the cost of cancer care in the United States: 2010-2020," Journal of the National Cancer Institute, vol. 103, no. 2, pp. 117-128, 2011.

[23] P. C. Wroe, J. A. Finkelstein, G. T. Ray et al., "Aging population and future burden of pneumococcal pneumonia in the United States," Journal of Infectious Diseases, vol. 205, pp. 1589-1592, 2012.

[24] P. A. Heidenreich, J. G. Trogdon, O. A. Khavjou et al., "Forecasting the future of cardiovascular disease in the United States: a policy statement from the American Heart Association," Circulation, vol. 123, no. 8, pp. 933-944, 2011.

[25] M. C. Odden, P. G. Coxson, A. Moran, J. M. Lightwood, L. Goldman, and K. Bibbins-Domingo, "The impact of the aging population on coronary heart disease in the United States," American Journal of Medicine, vol. 124, no. 9, pp. 827-833, 2011.

[26] S. Kurtz, K. Ong, E. Lau, F. Mowat, and M. Halpern, "Projections of primary and revision hip and knee arthroplasty in the United States from 2005 to 2030," Journal of Bone and Joint Surgery A, vol. 89, no. 4, pp. 780-785, 2007.

[27] P. Cram, X. Lu, S. L. Kates, J. A. Singh, Y. Li, and B. R. Wolf, "Total knee arthroplasty volume, utilization, and outcomes among medicare beneficiaries, 1991-2010," Journal of the American Medical Association, vol. 308, no. 12, pp. 1227-1236, 2012.

[28] S. Tepper and M. C. Hochberg, "Factors associated with hip osteoarthritis: data from the First National Health and Nutrition Examination Survey (NHANES-I)," American Journal of Epidemiology, vol. 137, no. 10, pp. 1081-1088, 1993.

[29] C. Cooper, H. Inskip, P. Croft et al., "Individual risk factors for hip osteoarthritis: obesity, hip injury, and physical activity," American Journal of Epidemiology, vol. 147, no. 6, pp. 516-522, 1998.

[30] K. M. Flegal, M. D. Carroll, R. J. Kuczmarski, and C. L. Johnson, "Overweight and obesity in the United States: prevalence and trends, 1960-1994," International Journal of Obesity, vol. 22, no. 1, pp. 39-47, 1998.

[31] A. H. Mokdad, M. K. Serdula, W. H. Dietz, B. A. Bowman, J. S. Marks, and J. P. Koplan, "The spread of the obesity epidemic in the United States, 1991-1998," Journal of the American Medical Association, vol. 282, no. 16, pp. 1519-1522, 1999.

[32] C. L. Ogden, M. D. Carroll, L. R. Curtin, M. A. McDowell, C. J. Tabak, and K. M. Flegal, "Prevalence of overweight and obesity in the United States, 1999-2004," Journal of the American Medical Association, vol. 295, no. 13, pp. 1549-1555, 2006. 
[33] T. D. Spector, F. Cicuttini, J. Baker, J. Loughlin, and D. Hart, "Genetic influences on osteoarthritis in women: a twin study," British Medical Journal, vol. 312, no. 7036, pp. 940-944, 1996.

[34] N. J. Manek, D. Hart, T. D. Spector, and A. J. MacGregor, "The association of body mass index and osteoarthritis of the knee joint: an examination of genetic and environmental influences," Arthritis and Rheumatism, vol. 48, no. 4, pp. 10241029, 2003.

[35] A. J. MacGregor, L. Antoniades, M. Matson, T. Andrew, and T. D. Spector, "The genetic contribution to radiographic hip osteoarthritis in women: results of a classic twin study," Arthritis and Rheumatism, vol. 43, no. 11, pp. 2410-2416, 2000.

[36] W. L. Healy, R. Iorio, J. Ko, D. Appleby, and D. W. Lemos, "Impact of cost reduction programs on short-term patient outcome and hospital cost of total knee arthroplasty," Journal of Bone and Joint Surgery A, vol. 84, no. 3, pp. 348-353, 2002.

[37] D. Iliopoulos, K. N. Malizos, and A. Tsezou, "Epigenetic regulation of leptin affects MMP-13 expression in osteoarthritic chondrocytes: possible molecular target for osteoarthritis therapeutic intervention," Annals of the Rheumatic Diseases, vol. 66, no. 12, pp. 1616-1621, 2007.

[38] N. Yamada, K. Cheung, S. Tilley et al., "Does epigenetics play a role in the pathology of osteoarthritis?" Journal of Bone \& Joint Surgery, vol. 88, pp. 403-403, 2006.

[39] D. T. Felson, Y. Zhang, J. M. Anthony, A. Naimark, and J. J. Anderson, "Weight loss reduces the risk for symptomatic knee osteoarthritis in women: the Framingham study," Annals of Internal Medicine, vol. 116, no. 7, pp. 535-539, 1992.

[40] W. H. Ettinger, R. Burns, S. P. Messier et al., "A randomized trial comparing aerobic exercise and resistance exercise with a health education program in older adults with knee osteoarthritis: the Fitness Arthritis and Seniors Trial (FAST)," Journal of the American Medical Association, vol. 277, no. 1, pp. 25-31, 1997.

[41] K. J. Bozic, P. Katz, M. Cisternas, L. Ono, M. D. Ries, and J. Showstack, "Hospital resource utilization for primary and revision total hip arthroplasty," Journal of Bone and Joint Surgery A, vol. 87, no. 3, pp. 570-576, 2005.

[42] J. Skinner, J. N. Weinstein, S. M. Sporer, and J. E. Wennberg, "Racial, ethnic, and geographic disparities in rates of knee arthroplasty among Medicare patients," New England Journal of Medicine, vol. 349, no. 14, pp. 1350-1359, 2003.

[43] M. G. E. Peterson, J. P. Hollenberg, T. P. Szatrowski, N. A. Johanson, C. A. Mancuso, and M. E. Charlson, "Geographic variations in the rates of elective total hip and knee arthroplasties among Medicare beneficiaries in the United States," Journal of Bone and Joint Surgery A, vol. 74, no. 10, pp. 15301539, 1992.

[44] B. Bashinskaya, B. V. Nahed, N. Redjal, K. T. Kahle, and B. P. Walcott, "Trends in peptic ulcer disease and the identification of Helicobacter Pylori as a causative organism: populationbased estimates from the US nationwide inpatient sample," Journal of Global Infectious Diseases, vol. 3, no. 4, pp. 366-370, 2011.

[45] B. P. Walcott, E. V. Kuklina, B. V. Nahed et al., "Craniectomy for malignant cerebral infarction: prevalence and outcomes in US hospitals," PLoS ONE, vol. 6, no. 12, Article ID e29193, 2011.

[46] C. Lavernia, D. J. Lee, and V. H. Hernandez, "The increasing financial burden of knee revision surgery in the United States," Clinical Orthopaedics and Related Research, no. 446, pp. 221226, 2006.
[47] E. Losina, R. P. Walensky, C. L. Kessler et al., "Costeffectiveness of total knee arthroplasty in the United States: patient risk and hospital volume," Archives of Internal Medicine, vol. 169, no. 12, pp. 1113-1121, 2009.

[48] J. H. Coben, C. A. Steiner, M. Barrett, C. T. Merrill, and D. Adamson, "Completeness of cause of injury coding in healthcare administrative databases in the United States, 2001," Injury Prevention, vol. 12, no. 3, pp. 199-201, 2006. 


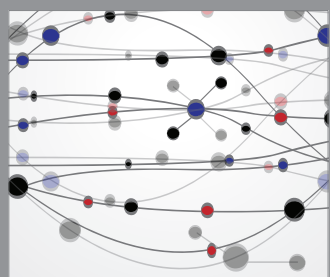

The Scientific World Journal
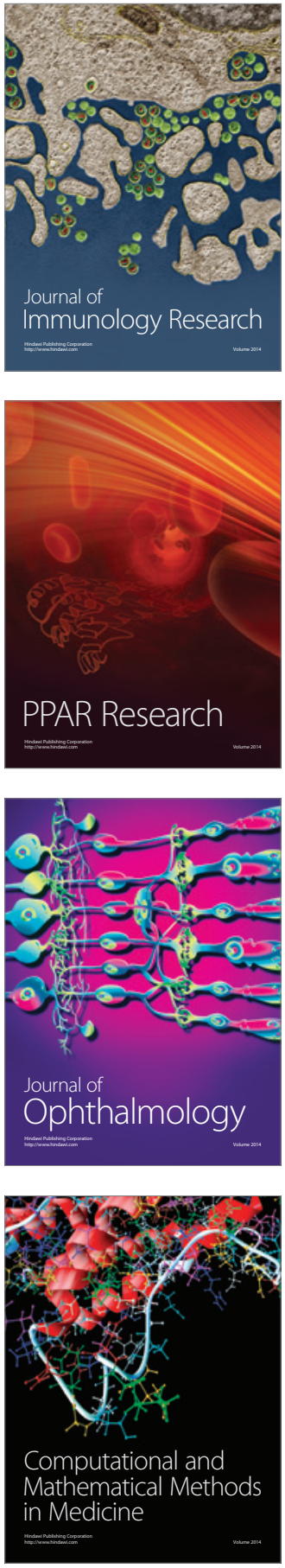

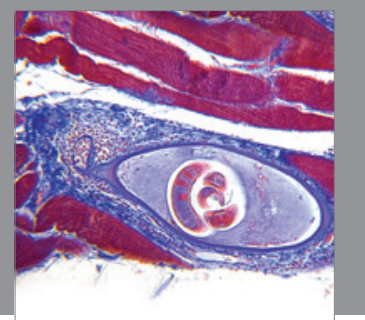

Gastroenterology

Research and Practice
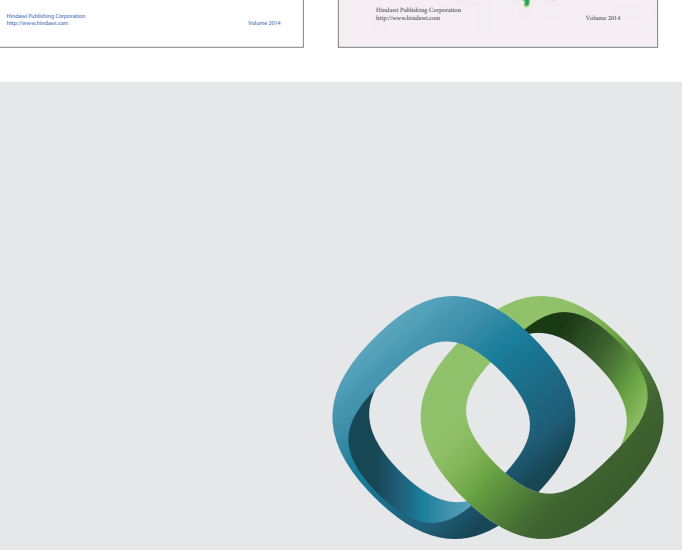

\section{Hindawi}

Submit your manuscripts at

http://www.hindawi.com
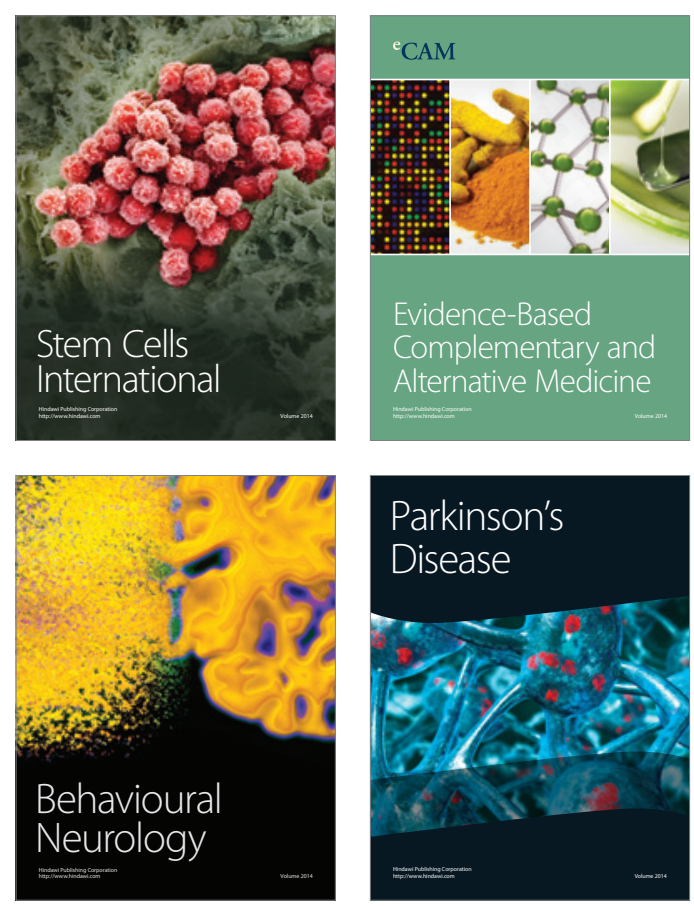

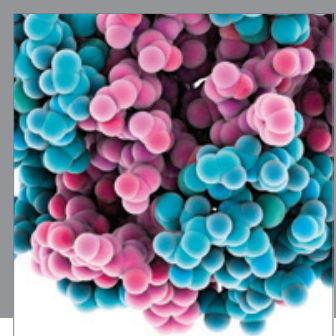

Journal of
Diabetes Research

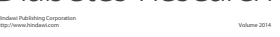

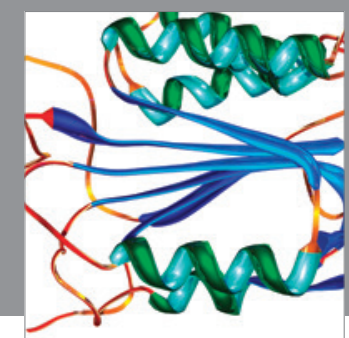

Disease Markers
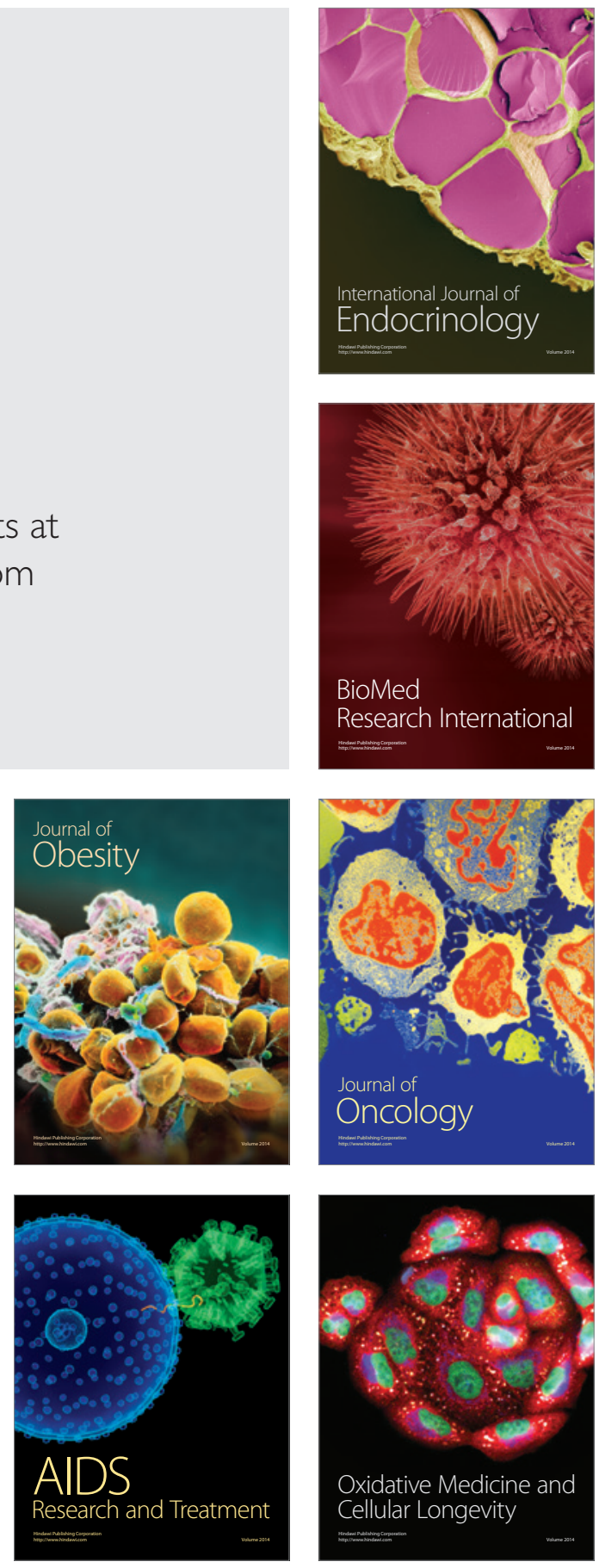